\title{
INFLUENCE OF LEARNING PREFERENCE ON SELF-EFFICACY AND Performance In MiXed-Modality First-YeAR ENGINEERING DESIGN
}

\author{
Jon-Michael J. Booth ${ }^{1}$, Thomas E. Doyle ${ }^{1}$, and David M. Musson ${ }^{2}$ \\ McMaster University, ${ }^{1}$ Department of Electrical and Computer Engineering and ${ }^{2}$ Faculty of Health Sciences \\ boothjj@mcmaster.ca, tdoyle@ieee.org, and musson@mcmaster.ca
}

\begin{abstract}
All students have preferences for the way they receive and distribute information when the objective is learning. These preferences can be shown to have an effect on self-efficacy and on performance. The relationships between learning preference, self-efficacy and performance were studied using survey and grade data obtained from a first-year Engineering Design and Graphics course. The students were placed in one of three groups according to the modality (type) of design project they were given; a Simulation-Based project (SIM) using a software simulation tool, a Prototyping project (PRT) using a $3 D$ printer, or a Simulation and Prototyping project (SAP) where they had to complete a design using both tools. Participants were given a custom survey that assessed self-efficacy and the VARK learning styles inventory which assesses learners on Visual, Aural, Read / Write and Kinesthetic learning preferences. 97 students were surveyed representing a response rate of $22.6 \%$. Student performance was assessed by examining scores on a subset of questions related to design visualization on the final examination for the course. Data analysis involved examining the correlation between learning style and self-efficacy, and scores on final examination for each of the three course modality groups. Findings from this study include higher performance for Kinesthetic learners assigned a simulation-based project and low performance for Read/Write learners with a prototyping project. This study supports the hypothesis that student performance may depend on learning preferences coupled with design project modality.
\end{abstract}

Keywords: engineering, learning, self-efficacy, first-year, design, performance, simulation, 3D printing.

\section{INTRODUCTION}

Engineering design is the creative integration of multiple techniques such as mathematics and software usage to achieve a tangible or theoretical construct. It is a skill that all engineers must master, and one of the most difficult skills to teach. Design projects provide a structured approach to the design process, giving students a solid understanding of how to move from a concept to a working model of a system. These projects not only give students the knowledge and skills to produce design outcomes, but are also believed give students confidence in future endeavors [20].

Engineering 1C03 Design and Graphics is a first-year engineering course at McMaster University. The course includes a lecture component on design background and theory; a tutorial focusing on hand-sketching, calculations, and design on paper; and a computer lab session where students get hands-on experience with solid modelling software (AutoDesk Inventor) and a physical modelling and system simulation application (MapleSim). Students also have access to 3D rapid-prototype printers (RepRapPro Huxley) where they can freely experiment with exporting computer models to solid plastic models they can hold. The course concludes with a design project in one of three modalities; a Simulation-Based project (SIM) using a software simulation tool, a Prototyping project (PRT) using a 3D printer, or a Simulation and Prototyping project (SAP) where they had to complete a design using both tools.

This study explores the hypothesis that engineering design projects may increase self-efficacy, which in turn can lead to increased performance in the form of better grades on project-related exam questions. Differences in design project modality may affect self-efficacy, particularly for students with varied preferences for learning. The goal of this study is to understand the way that engineering students learn and determine whether factors such as design project modality can affect selfefficacy and ultimately performance.

\subsection{Background}

The VARK learning styles assessment inventory, developed by Fleming [1] provides a means to identify and quantify learning preferences in students. Participants show preference for Visual learning (V) using maps, 
graphs, charts and symbols, Aural/Auditory learning (A) preferring lectures, discussion and radio, Read/Write learning (R) using books, the internet, and other printed material, and Kinesthetic learning $(\mathrm{K})$ preferring a more practical, hands-on approach with simulation, video and demonstrations.

These preferences should not be confused with strengths, but can be used to enhance students' abilities to learn new information based on the way it is presented. The 1C03 course which was surveyed for this study has been undergoing a number of changes over the past several years, seeing the inclusion of new technologies designed to increase student interest in course material. The authors saw an excellent opportunity to study these students and the effects and benefits directly inspired by these changes.

Self-efficacy, the belief in one's own abilities to achieve a desired outcome, was chosen as another key attribute in the study based on previous work in that area. The desire was to promote positive changes in confidence and efficacy levels through interesting and modern changes to the course, and thereby increase engagement and performance.

Student reaction to 3D printers, illustrated in Figure 1, has been exceptional and including these printers in the course has been generally regarded as a positive learning experience for the students. The surveys given were designed to quantify these experiences and provide insight into all aspects of the course and into the Engineering learning curriculum as a whole, as well as to identify whether some groups of learners gain more than others.

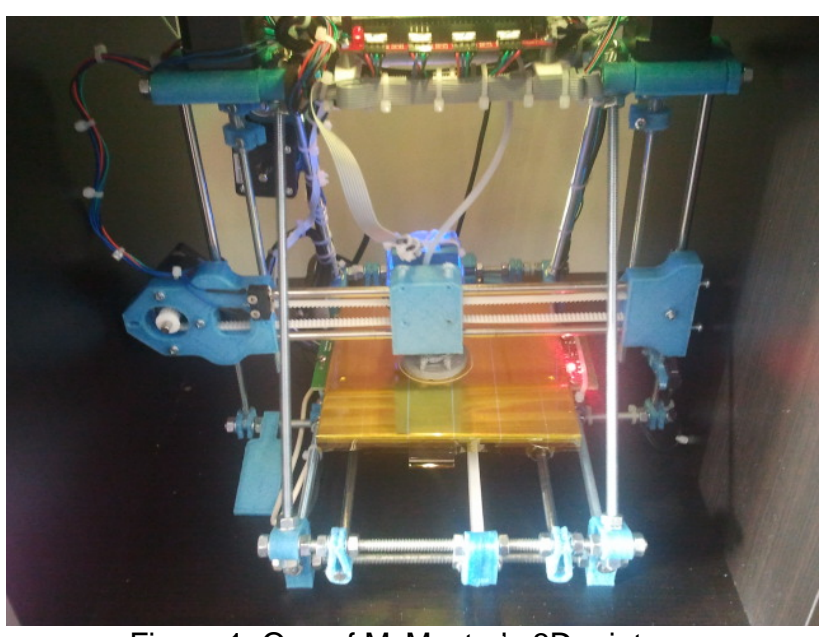

Figure 1: One of McMaster's 3D printers

\subsection{Literature Review}

Among the various learning style models, the authors chose the VARK developed by [1] Fleming as the most appropriate for this study. In particular, it was the distinction between kinesthetic preferences on the one hand the aural and reading preferences that best aligned with the introduction of 3-D prototyping that made the VARK an intuitively satisfying model for this study. A practical benefit for choosing the VARK included its online and no cost availability [19].

The VARK questionnaire is among the most popular learning style inventories for quantifying learning preference, for example being used to study curriculum changes affect students with different styles of learning [2]. Another study was conducted upon students in Chemical Engineering [3] and demonstrated a higher preference for hands-on (Kinesthetic) learning amongst Engineers. Materials Science students were given the survey [4] in relation to an interactive tool introduced into the classroom, which was also preferred by K-type learners. Research has also been done linking learning style to performance. This includes a study [5] in an introductory Astronomy class which identified learning preference as a critical factor in success. Other studies have discovered relationships between learning styles and performance such as one involving game design and programming [6] which showed that visual learners (Vtype) have higher engagement. A study involving marketing students [7] showed that not only were a variety of sources required to appeal to the diverse learning preferences in the classroom, but that student performance differed with learning style.

Self-efficacy and social cognitive theory [8] made popular by Albert Bandura at Stanford University suggests positive thinking promotes positive outcomes. Studies have shown a positive correlation between selfefficacy and performance, such as a study [9] showing that health improvements correlated with self efficacy, and another study showing that individual achievement in a team environment is linked to self-efficacy [10]. In another study, previous computer experience can positively impact first-time Java programmers [11] and another survey identifying self-efficacy factors in firstyear Engineering students [12]. Another study [13] found that self-efficacy can affect emotional responses and outcome expectations. One study indicated that incoming university Engineering students with high-school Engineering experience have a higher self-efficacy [14]. Other studies show how course changes can reflect on self-efficacy scores [15]. Self-efficacy changes can be observed at all experience levels, and can be shown to accurately predict engineering experience levels [16]. Student contribution and effort, speed of task completion, and grades have been shown to be affected by selfefficacy [17]. The authors' decision to create a unique self-efficacy survey was based on these factors, and was based upon Bandura's own guide for creating unique selfefficacy scales [18]. 


\subsection{Problem Definition}

Changes to a course are accompanied by a change in thinking. Many factors can affect student outcomes and outcome expectancies, especially when introducing new and never-before-tried methods for instruction, demonstration, and experience in and out of the classroom. Reactions from students can vary, including changes in self-efficacy and performance. Both learning preference and self-efficacy have been shown to have an effect on performance. The authors proposed to study the relationship between learning preference and selfefficacy, and to study changing self-efficacy over the course of the term. These changes will be related to performance scores obtained from the final exam with questions directly related to the material learned throughout the design project.

As learning preference varies from student to student, these changes can be categorized to see what effects have been had on students in every learning style category. Additionally, different students have been given different design projects, and more investigation is possible by observing the effects of modality and how these factors combine to affect overall performance.

\subsection{Solutions Considered}

This paper aims to study the differences between groups in each of four learning preference categories (Visual, Aural/Auditory, Read/Write and Kinesthetic). It also studies students grouped by design project modality (Simulation Only [SIM], Prototyping Only [PRT], and Simulation and Prototyping [SAP]).

Previous research by the authors used a single survey, given to students who were actively involved in the course and students who had completed the course. This effectively split the population into two groups which could be compared, but had the drawback of non-paired results. Each student surveyed was either completed the course or currently taking it, so two distinct populations emerged. The numbers in each group were different, and more importantly the students themselves were different.

It was felt that to obtain more significant results, a single population be used and tested twice with some time between them. This led to the creation of a two-survey system, where students could be surveyed at the beginning of a course and again at the end to maintain a consistency from student to student.

\section{METHODS}

\subsection{Selected Methodologies}

Two surveys were created and offered to all students taking Engineering 1C03 Design and Graphics, a required first-year Engineering course at McMaster University. The first survey, delivered in September 2012 consisted of 10 self-efficacy questions which asked students to rate agreement or disagreement on a Likert eleven-point scale, based on Bandura's own scales [18]. The second survey, delivered in December 2012 to the same students, included the same 10 self-efficacy questions as well as the 16-question VARK survey by Fleming [19]. The surveys were delivered online by way of the student-accessed course CMS and were each available for a period of one to two weeks.

The self-efficacy questions were created from five identified sources of self-efficacy; mastery experiences, vicarious experiences, social persuasions, physiological states and drive and motivation. The VARK survey identifies the four learning style preferences; Visual, Aural/Auditory, Read/Write and Kinesthetic.

Additional questions were added to each survey related to other studies, such as Academic Motivation. The results obtained from these additional questions are not given here, but may be a part of future work.

\subsection{Expected Significance of This Work}

This paper will explore the results obtained from the surveys and examine the differences between self-efficacy scores at the beginning of the term and the end of the term as well as how these differences break down in terms of learning preference and assigned project modality. Additionally, performance data in the form of grades obtained from project-related questions on the final exam will be examined and included in the results broken down by learning preference and project modality.

The results obtained will provide valuable insight for educators and course designers working with first-year engineering students who wish to evaluate the learning styles and possible changes in self-efficacy and performance in students brought about by course changes.

\section{RESULTS}

The surveys were offered in the Fall 2012 term to a class of 429 first-year Engineering students. The survey was voluntary, and as such received 97 valid respondents who completed both surveys and were eligible for inclusion in this study (22.6\%). The chance to win a 3D printer was offered to all students as an incentive to participate in this study, however the McMaster Research Ethics Board did not allow the lottery to be restricted to only those students who completed the survey.

\subsection{Learning Preference}

The distribution of learning styles was diverse among the respondents, as shown in Figure 2. There were 21 pure 
V-learners, higher than any other category. There were 16 A-learners, 18 R-learners and 20 K-learners.

There were 21 multimode learners, a subset that is found to be common when using the VARK survey. Of the multimode learners, 38 showed V-type tendencies, 26 had A-type, 26 had R-type and 30 had K-type. The results obtained and shown in this paper consider multimodal students to be members of all associated groups.

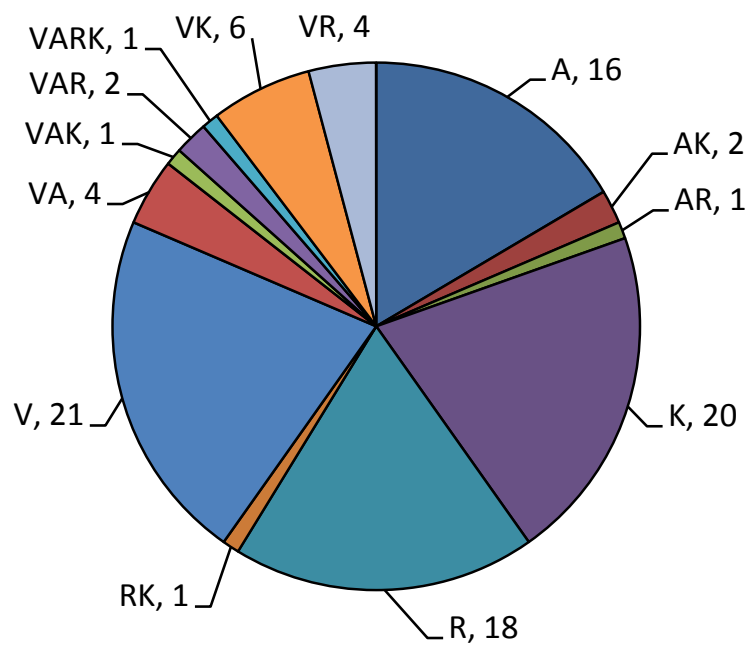

Figure 2: Learning preference class distribution

\subsection{Self-Efficacy}

Table 1 shows the average self-efficacy scores obtained from the first survey given at the start of term (Time 1), the scores obtained from the second survey given at the end of term (Time 2), and the mean average increase in scores from Time 1 to Time 2. The averages are grouped by learning preference and the total class averages are also given.

V-type learners had the lowest average starting selfefficacy but also showed the highest increase in selfefficacy from Time 1 to Time 2. R-type learners had the highest average in Time 1 and Time 2. A-type learners had the lowest average at Time 2, and K-type learners had the lowest increase in self-efficacy from T1 to T2.

Table 1: Average Self-Efficacy by Learning Preference

\begin{tabular}{|l|c|c|c|}
\cline { 2 - 4 } \multicolumn{1}{c|}{} & $\mathrm{T} 1$ & $\mathrm{~T} 2$ & INCR \\
\hline $\mathrm{CLASS}$ & 7.321 & 7.961 & $0.641^{*}$ \\
\hline $\mathrm{V}$ & 6.956 & 7.939 & $0.983^{*}$ \\
\hline $\mathrm{A}$ & 7.118 & 7.898 & $0.780^{\star *}$ \\
\hline $\mathrm{R}$ & 7.404 & 8.136 & $0.733^{*}$ \\
\hline $\mathrm{K}$ & 7.258 & 7.954 & $0.696^{\star *}$ \\
\hline${ }^{\star *} \rho<0.01$ & \multicolumn{3}{l}{} \\
${ }^{*} \rho<0.001$ & \multicolumn{4}{l}{}
\end{tabular}

Table 2 shows the average self-efficacy scores grouped by design project modality. The Simulation group [SIM] had the lowest average at Time 2 and the lowest increase in self-efficacy. The Prototyping group [PRT] had the lowest average at Time 1 and the highest at Time 2 and also showed the largest increase. The Simulation and Prototyping Group had the largest self-efficacy at Time 1.

Table 2: Average Self-Efficacy by Modality

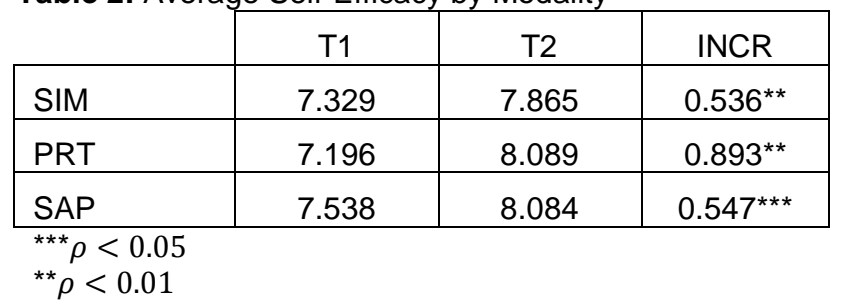

Figure 3 shows a graphical representation of the results for all learning preference types and modalities.

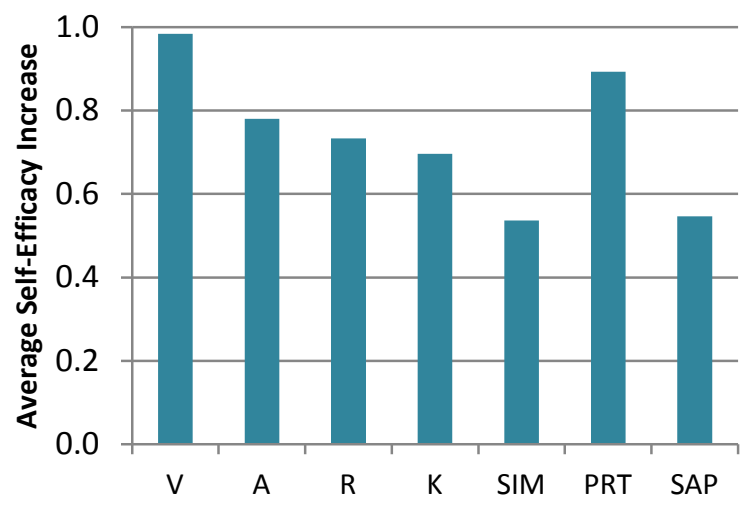

Figure 3: Self-efficacy increase by category

\subsection{Performance Grade Data and Correlation}

From the final exam, 15 math-based questions related to the final project were chosen. The mean average for all students was $74.502 \%$ with a standard deviation of 15.841 percentage points. The distribution of grades is shown in Figure 4.

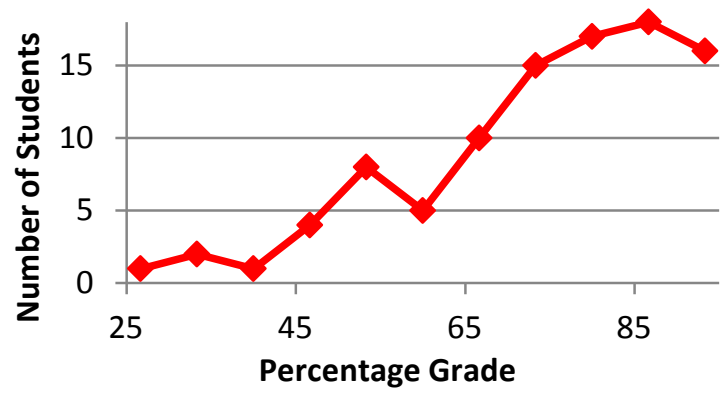

Figure 4: Grade distribution 
Table 3 shows the average grades obtained grouped by learning preference category and also the correlation coefficient between performance data and increase in selfefficacy. Visual learners had the highest performance but showed a negative correlation with self-efficacy. Aural/Auditory learners had the highest correlation. Read/Write learners had the lowest performance average. Kinesthetic learners had a high average but showed a low positive correlation.

Table 3: Performance and Self-Efficacy Correlation

\begin{tabular}{|l|c|c|}
\cline { 2 - 3 } \multicolumn{1}{c|}{} & AVG & CORR $^{*}$ \\
\hline CLASS & 74.502 & 0.334 \\
\hline V & 78.462 & -0.096 \\
\hline A & 75.309 & 0.292 \\
\hline$R$ & 70.123 & 0.172 \\
\hline$K$ & 76.559 & 0.053 \\
\hline
\end{tabular}

${ }^{\star} \rho<0.001$

Table 4 shows the average grades obtained grouped by project modality and also the correlation coefficient between performance data and increase in self-efficacy. Simulation students [SIM] and Simulation and Prototyping students [SAP] had high performance averages. Prototyping students [PRT] had the highest correlation but had the lowest overall average. Simulation and Prototyping students [SAP] also showed a negative correlation.

Table 4: Performance and Self-Efficacy by Modality

\begin{tabular}{|l|c|c|}
\cline { 2 - 3 } \multicolumn{1}{c|}{} & AVG & CORR* \\
\hline ALL & 74.502 & 0.334 \\
\hline SIM & 77.091 & 0.128 \\
\hline PRT & 68.095 & 0.211 \\
\hline SAP & 77.143 & -0.103 \\
\hline
\end{tabular}

${ }^{*} \rho<0.001$

Figures 5 and 6 show the performance and correlation results graphically for all categories.

\subsection{Combined Learning Preference and Modality}

Table 5 shows the increases in self-efficacy from Time 1 to Time 2 for students with various learning preferences according to the design project modality to which they were assigned.

V-PRT students (Visual learners assigned to the Prototyping modality) show the highest increase in selfefficacy. K-SAP students (Kinesthetic Simulation and Prototyping) show the lowest increase.

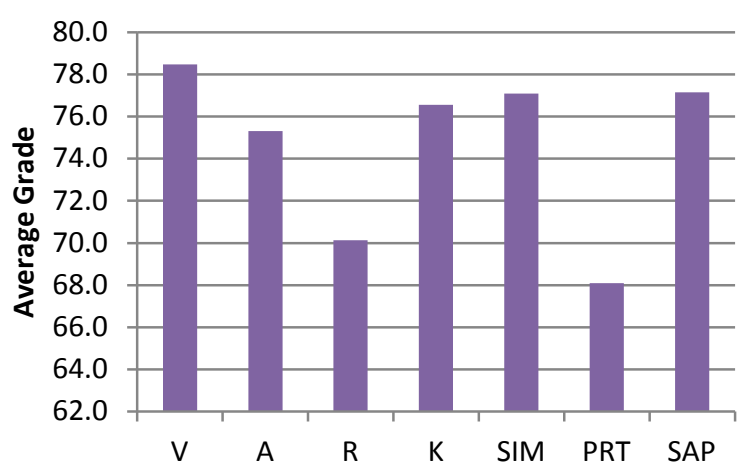

Figure 5: Performance by category

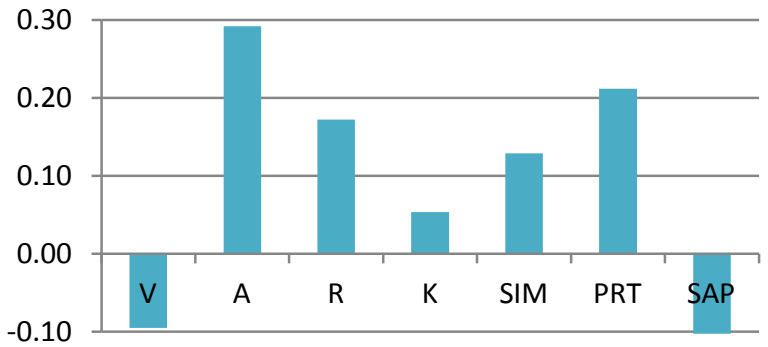

Figure 6: Correlation of self-efficacy and performance

Table 5: Self-Efficacy Increase by Learning Preference

\begin{tabular}{|c|c|c|c|}
\hline & SIM & PRT & SAP \\
\hline V & $0.743^{\star *}$ & $1.933^{*}$ & 0.321 \\
\hline A & 0.688 & $1.104^{\star \star \star}$ & 0.545 \\
\hline $\mathrm{R}$ & $0.476^{\star \star *}$ & $0.955^{\star \star \star}$ & $1.188^{* *}$ \\
\hline K & $0.918^{\star \star \star}$ & 0.700 & 0.136 \\
\hline
\end{tabular}

The results are presented visually in Figure 7.

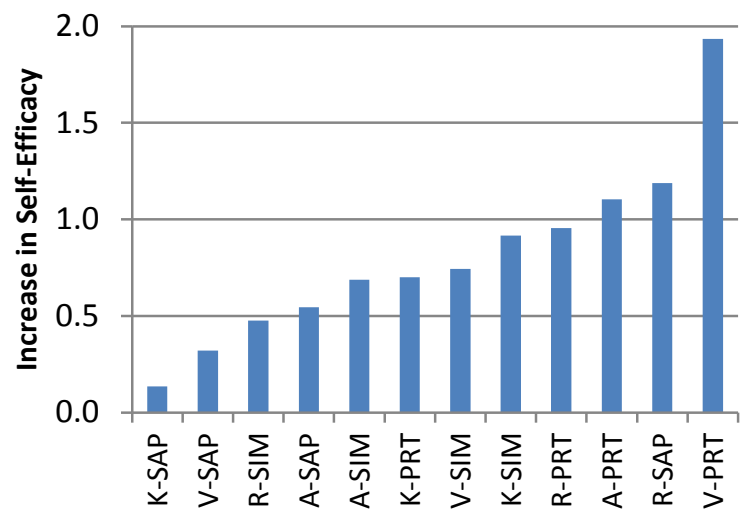

Figure 7: Increase in self-efficacy by category 
Table 6 shows the average performance on projectrelated exam questions for students with various learning preferences according to the design project modality to which they were assigned.

Table 6: Performance by Learning Preference

\begin{tabular}{|l|c|c|c|}
\cline { 2 - 4 } \multicolumn{1}{c|}{} & SIM & PRT & SAP \\
\hline $\mathrm{V}$ & 78.841 & 77.333 & 78.889 \\
\hline $\mathrm{A}$ & 73.333 & 80.952 & 73.333 \\
\hline $\mathrm{R}$ & 76.190 & 59.333 & 77.778 \\
\hline $\mathrm{K}$ & 81.333 & 68.000 & 78.889 \\
\hline
\end{tabular}

K-SIM students (Kinesthetic Simulation) showed the highest performance average, with A-PRT students (Aural/Auditory Prototyping) very close behind. R-PRT students (Read/Write Prototyping) had the lowest total average.

The results are presented graphically in Figure 8.

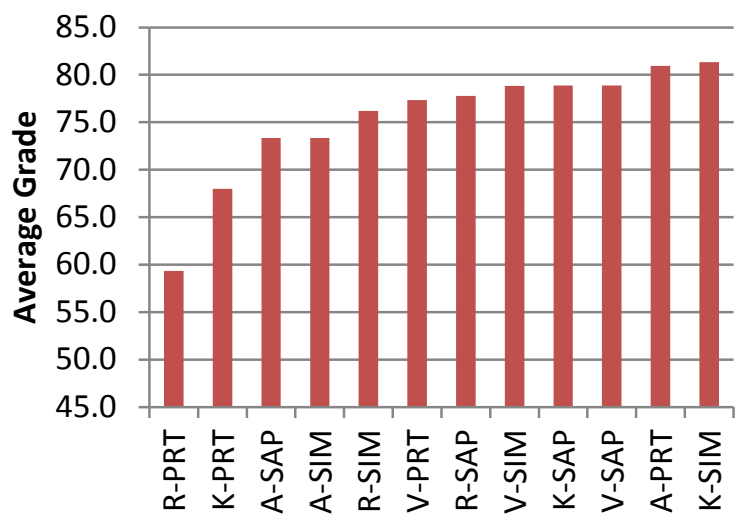

Figure 8: Performance by category

\section{DISCUSSION}

\subsection{Increases in Self-Efficacy}

Self-efficacy scores were higher than expected values based on our previous study [20]. Additionally, all learning preference categories and all modalities showed an average increase in self-efficacy from the beginning of term to the end of term, as shown in Figure 3.

Visual learners showed the highest increase in selfefficacy by learning preference, as well as the highest overall increase. The Design and Graphics course is a highly visual course focusing on visualization techniques, so this result makes sense. The prototyping group saw the second highest overall average increase, as well as the highest increase by modality. This could be explained by the "wow" factor of the introduction to new technology that had never before been used for a first-year design project.

\subsection{Performance Grade Data}

Grade data was obtained from visualization and calculation-based questions related to the project focus of gear design on the final exam. All students were required to learn about simulation and prototyping but only some were selected to complete the final design project using each modality. The population was divided as $60 \%$ Simulation [SIM], 20\% Prototyping [PRT] and 20\% Simulation and Prototyping [SAP].

For learning preference, grades show a noticeable difference for Read/Write learners (Figure 5). This may be explained by way that the course appeals more to Visual (and Kinesthetic) learners by its nature and by the recent additions of hands-on design projects.

The Prototyping group [PRT] shows the largest grade difference compared to the Simulation and Prototyping [SAP] and pure Simulation [SIM] groups. This may be explained by way that the simulation component makes calculation errors more obvious. Errors and tolerance problems revealed by the simulation may cause students to actively re-examine the mathematics involved to accurately solve design problems, which can lead to a greater understanding and ultimately increased performance on calculation-type exam questions. Aural/Auditory learners assigned to Prototyping (A-PRT) show one of the highest average grades and may be immune to this phenomenon. Read/Write learners assigned a Prototyping project (R-PRT) had the lowest overall average, which may indicate a lower visualization capability for R-type learners.

\subsection{Self-Efficacy / Performance Correlation}

In general, studies show positive correlation between self-efficacy and performance [8]. Aural/Auditory learners have the greatest positive self-efficacy to performance correlation by learning preference, and the prototype modality shows the greatest positive correlation for project type. Figure 6 shows the correlation coefficients graphed for self-efficacy and performance by category. Any correlation coefficient greater than 0.3 is generally considered significant, however in this study there is no such result. This may be explained by the low response rate of the survey and the small sample size. The graph is included for reference.

\subsection{Learning Preference and Modality}

The results presented give a good overall picture of the effects of learning preferences and project modality on self-efficacy and performance. The following section shows the added effects of merging these data sets.

Visual learners, despite showing an initially low average self-efficacy, showed a significant increase in self-efficacy as the term progressed. Coupled with similar 
data shown for the Prototype modality, the result for VPRT group members is a very large increase in selfefficacy amounting to almost double the next highest group. In contrast, K-SAP students (who are Kinesthetic learners assigned the Simulation and Prototyping Modality) show a very low increase in self-efficacy.

Self-efficacy in this study does not correlate well with performance, contrary to Bandura's social cognitive theory [8] which is likely a factor of small sample and sub-sample size. V-PRT students, for example who have a high average increase in self-efficacy, show only an average performance on project related exam questions falling almost exactly at the mean class average. R-PRT students (Read/Write learners assigned the Prototyping modality) with an above average increase in self-efficacy perform the weakest in the class by a large margin. KSIM students (Kinesthetic learners - Simulation modality) perform the greatest despite an average increase in selfefficacy.

\section{CONCLUSIONS}

Design project differences and changes to a course can have observable effects on a student population. These effects can be seen through differences in self-efficacy and performance. The effects can also be influenced by student learning preferences.

In this study it is shown that students with Visual learning tendencies may have higher self-efficacy and perform better in a course with a high visual component. It is also shown that students with high self-efficacy in a prototyping modality may not perform as well as expected.

This study also suggests that there are some combinations of learning preference and design project modality which are well or poorly suited for combination. One such poor combination might be Read/Write learners with a hands-on prototyping project, while a well-suited combination would be Kinesthetic learners with a purely simulation design project.

\section{Acknowledgements}

This paper and the research supporting it were made possible by funding from HEQCO, the Higher Education Quality Council of Ontario, support from Studica, and Maplesoft. The authors would also like to thank the Engineering 1 program at McMaster University for their support, and the first-year engineering student body at McMaster for their assistance in completing the survey.

\section{References}

[1] N. D. Fleming and C. Mills (1992), Not Another Inventory, Rather a Catalyst for Reflection, To Improve the Academy, Vol. 11, page 137, 1992.
[2] D. Jensen and M. Bowe, "Hands-on experiences to enhance learning of design: Effectiveness in a redesign context when correlated with MBTI and VARK types," (Cahrlotte, NC, United states), pp. 2585-2607, 1999.

[3] S. A. Driscoll and C. E. Garcia, "Preferred learning styles for engineering students,” (St. Louis, MO, United states), pp. 4801-4810, 2000.

[4] C. Demetry, "Understanding interactions between instructional design, student learning styles, and student motivation and achievement in an introductory materials science course," in Frontiers in Education, 2002. FIE 2002. 32nd Annual, vol. 3, pp. S1H-8 vol.3, Nov 2002.

[5] S. Kellogg, D. Durben, and S. Ayars-Junek, "Critical factors for success in an introductory astronomy class," in Frontiers in Education, 2004. FIE 2004. 34th Annual, pp. T1F-3-8 Vol. 1, Oct 2004.

[6] C.-K. Chang, T.-Y. Chuang, and W.-L. Kuo, "Relationships between engagement and learning style for using VPL on game design,” in Digital Game and Intelligent Toy Enhanced Learning (DIGITEL), 2012 IEEE Fourth International Conference on, pp. 153-155, March 2012.

[7] M. Kastner and B. Stangl, "Mapping learning aids and introducing learning styles as a moderator," in System Sciences (HICSS), 2011 44th Hawaii International Conference on, pp. 1-10, Jan 2011.

[8] A. Bandura (1994). Self-efficacy. In V. S. Ramachaudran (Ed.), Encyclopedia of human behavior (Vol. 4, pp. 71-81). New York: Academic Press. (Reprinted in H. Friedman [Ed.], Encyclopedia of mental health. San Diego: Academic Press, 1998).

[9] V. J. Strecher, B. McEvoy DeVellis, M. H. Becker, and I. M. Rosenstock, "The role of self-efficacy in achieving health behavior change,” Health Education \&Behavior, vol. 13, no. 1, pp. 73-92, 1986.

[10] S. Purzer, "The relationship between team discourse, selfefficacy, and individual achievement: A sequential mixedmethods study,” Journal of Engineering Education, vol. 100, no. 4, pp. 655-679, 2011.

[11] P. Askar and D. Davenport, "An investigation of factors related to self-efficacy for java programming among engineering students," The Turkish Online Journal of Educational Technology-TOJET, vol. 8, no. 1, p. 26, 2009.

[12] M. A. Hutchison, D. K. Follman, M. Sumpter, and G. M. Bodner, "Factors influencing the self-efficacy beliefs of first-year engineering students," Journal of Engineering Education, vol. 95, no. 1, pp. 39-47, 2006.

[13] D. Compeau and C. Higgins, "Computer self-efficacy: development of a measure and initial test," Management Information Systems Quarterly, vol. 19, no. 2, pp. 189-211, 1995/06. 
[14] T. D. Fantz, T. J. Siller, and M. A. Demiranda, "Precollegiate factors influencing the self-efficacy of engineering students,” Journal of Engineering Education, vol. 100, no. 3, pp. 604-623, 2011.

[15] D. Luo and D. Heer, "Junior-level design experiment in a 10 week analog design course,” (Piscataway, NJ, USA), pp. 5 pp., 2010.

[16] A. R. Carberry, H.-S. Lee, and M. W. Ohland, "Measuring engineering design self-efficacy,” Journal of Engineering Education, vol. 99, no. 1, pp. 71-79, 2010.

[17] M. A. Hutchison-Green, D. K. Follman, and G. M. Bodner, "Providing a voice: Qualitative investigation of the impact of a first-year engineering experience on students' efficacy beliefs,” Journal of Engineering Education, vol. 97, no. 2, pp. 177-190, 2008.
[18] Albert Bandura, "Guide for constructing self-efficacy scales," in Self-Efficacy Beliefs of Adolescents, Frank Pajares (ed.) and Tim Urdan (ed.). Information Age Publishing, Inc., 2006, 368 pp.

[19] N. D. Fleming. "VARK: A Guide To Learning Styles.” Internet: www.vark-learn.com, 2011. [April 28, 2013].

[20] J. J. Booth and T. E. Doyle, "Importance of first-year engineering design projects to self-efficacy: Do first-year students feel like engineers?” in Proc. 2nd Canadian Engineering Education Association Conf., CEEA12, W. Kinsner (ed.) (Winnipeg, MB; June 17-20, 2012) ISBN 9781-927697-00-9, pp. 162-169, 2012. 